\title{
LA ARMADURA LEGAL: EL MARCO JURIDICO DE LAS RELACIONES IGLESIA-ESTADO EN LOS PRIMEROS AÑOS DEL FRANQUISMO
}

Nieves Montesinos Sánchez

Universidad de Alicante

I- La revista "Razón y Fe", saludaba la victoria terminada la guerra en los siguientes términos: "Franco es el hombre. Con esto está dicho todo. El hombre a quien miraron dos siglos de sueños y añoranzas, y el hombre a quien la nueva Era española debe su porvenir, porque Franco es el hombre que crea históricamente un nuevo dia, una nueva atmósfera, un nuevo sol. En la España de Franco se vive, se respira, se ve de otra manera. Somos, por obra y gracia de Franco, lo que no éramos y debíamos ser. El ha cambiado nuestra esencia histórica. Llamemos a Franco Nuestro Caudillo. Puesto que él nos guía por caminos insólitos de gloria y de historia, reservémosle la palabra que hace muchos siglos vive intacta de uso oficial. Así viene más pura y más significativa. ¡Franco! ¡Nuestro Caudillo!"! .

Progresivamente, al menos en su formulación externa, en sus manifestaciones públicas, la proximidad entre el régimen del General Franco y la Iglesia se fue haciendo cada vez más evidente. Puesto que el poder civil y militar no podía asumir por sí sólo la inmensa labor de propaganda y recuperación de las poblaciones, la aportación fundamental de la Iglesia vendría dada por la matización religiosa y cristiana que iría inundando poco a poco, paulatinamente, la sociedad española. El Nuevo Estado utilizaba una política restauracionista en el terreno religioso y se iba definiendo como católico. La Iglesia, por su parte, se sentía satisfecha ante esa vuelta a la tradición española católica ${ }^{2}$.

En efecto, ya antes de finalizar la guerra, en la zona nacional se dictan diversas disposiciones tendentes a dejar sin efecto las correspondientes republicanas. En el ánimo estaba el que las cosas volvieran a su sitio, 'trastocadas' como habían estado en el paréntesis republicano. Igualmente se inician los primeros contactos y negociaciones con la Santa Sede a fin de llegar a la firma de un Acuerdo o Concordato $^{3}$, lo que podría suponer un apoyo decisivo para el Régimen del que estaba necesitado cuando menos en el ámbito internacional.

\footnotetext{
1 "Razón y Fe", julio-agosto de 1939, p. 235.

${ }^{2}$ Cfr. J. M. LABOA, Iglesia y religion en las constituciones españolas. Encuentro, Madrid, 1981.

${ }^{3}$ Uno de los mejores estudios de los primeros años de negociaciones entre el régimen del General Franco y la Santa Sede lo constituye la obra de A. MARQUINA BARRIO, La diplomacia vaticana y la España de Franco (1936-1945). C.S.I.C., Madrid, 1986.
} 
II- Conviene recordar que al advenimiento de la II República Española de 1931 estaban vigentes la Constitución de 1875 y el Concordato de 1851. La constitución fue derogada pero no así el Concordato que fue simplemente incumplido, sin que mediara ninguna denuncia formal.

De modo que cuando a partir de 1936 y, sobre todo, de 1939, el nuevo Estado nacido de la guerra civil inicia su andadura jurídica lo hace sin condicionamiento constitucional alguno -no lo iba a ser, evidentemente, la Constitución republicana de 1931-; pero en cambio resultaba dudoso determinar la vigencia o no del Concordato decimonónico ${ }^{4}$. No denunciado, simplemente incumplido y violado por la República, la Santa Sede había, de hecho, procedido al margen del mismo en sus relaciones con la España republicana, dado que pudo ella misma denunciar el incumplimiento y la violación y que optó por la via pragmática de actuar a su margen ${ }^{5}$-sin retirar al Nuncio, que lo fue durante la República el mismo que fuera durante los anteriores períodos de la Monarquía constitucional y de la Dictadura del General Primo de Rivera, Monseñor Federico Tedeschini-, cabía pensar en una derogación fáctica, por denuncia de hecho de ambas partes a mantenerlo en vigor, de aquel ya secular Concordato de Isabel $\mathrm{II}^{6}$.

El tema de fondo era pues, una vez desaparecidas las circunstancias adversas que impidieron la aplicación del Concordato de 1851, determinar el mantenimiento o no del mismo como normativa rectora de las relaciones entre la Iglesia Católica y el Nuevo Estado surgido del alzamiento nacional. Ante la imposibilidad del acuerdo, la cuestión se centra de manera fundamental en el paso del Concordato de 1851 al de 1953, en el que quizá las circunstancias históricas del momento impidieron actualizar el contenido y el marco de las relaciones Iglesia-Estado en consonancia con los nuevos principios.

Así, el tránsito entre uno y otro estuvo jalonado por una serie de Acuerdos parciales, por los que, si bien en principio no se resolvía la vigencia del Concordato del 51, sí se intentaban resolver problemas puntuales sobre materias de interés común.

El primero en el tiempo y probablemente también en importancia fue el Acuerdo

\footnotetext{
${ }^{4}$ Se enfrentaban dos posturas irreconciliables. Para el gobiemo del General Franco el Concordato era perfectamente válido y no podía derogarse unilateralmente, para la Santa Sede por el contrario el Concordato había dejado de existir. J. GIMENEZ Y MARTINEZ DE CARVAJAL, prólogo a la obra de A. MARQUINA, pp. 17-19.

s E. F. REGATILLO, El Concordato Español de 1953. Sal Terrae, Santander, 1961, p. 115.

${ }^{6}$ Consta que tanto políticos de derechas como de izquierdas, e incluso el propio Alcalá Zamora, se cuestionaron qué se debía hacer con el Concordato de 1851 , y hasta se barajó la posibilidad de un nuevo acuerdo. Vid. en este sentido: V. M. ARBELOA, "El proyecto de Concordato del Rodia Postius en 1934", REDC (1973), p. 82; "En tomo al 'Modus Vivendi'de España con el Vaticano de 1934", REDC (1977), pp. 95-96.

${ }^{7}$ Los diferentes Acuerdos fueron cronológicamente, los siguientes: Ácuerdo sobre el modo de ejercicio del Privilegio de Presentación (de 7 de junio de 1941); Acuerdo para la provisión de beneficios no consistoriales (de 16 de julio de 1946); Acuerdo sobre Seminarios y Universidades de Estudios Eclesiásticos (de 8 de diciembre de 1946); Acuerdo sobre la Jurisdicción castrense y asistencia religiosa a las fuerzas Amadas (de 5 de agosto de 1950).
} 
sobre el modo de ejercicio del privilegio de presentación entre el Gobierno español y la Santa Sede, de 7 de junio de $1941^{8}$.

En él se conserva el Derecho de Patronato. La fórmula que le sirvió de base fue el sistema que había sido puesto en práctica por la Junta del Real Patronato en tiempos de la Dictadura de Primo de Rivera; pero modificada en un sentido quizá más favorable para el Estado, ya que se prescinde de las listas previas sobre las que el Gobierno debía elegir necesariamente. El procedimiento de selección, complicado y obra personal de Pio XII, daba garantias suficientes a la Santa Sede sobre la idoneidad de los candidatos. Una vez llegados a un acuerdo el Nuncio y el Gobierno sobre una lista de al menos seis personas, el Papa elegiría tres de los propuestos que comunicaría al Gobierno para que el Jefe del Estado en el término de treinta días presentara oficialmente uno de los tres. Si el Papa no pudiere elegir de entre la lista de tres por no considerarla aceptable, podría por propia iniciativa completar y formular una terna de candidatos, comunicándola por medio del Nuncio al Gobierno. En cualquier caso todas estas negociaciones previas tendrían carácter absolutamente secreto, guardándose de manera especial el secreto con respecto a las personas hasta el momento de su nombramiento 9 .

Aún a pesar de que el procedimiento sobre el modo de ejercicio del privilegio de presentación había sido acordado por las Altas Partes, ello no trajo consigo como podía esperarse la desaparición total de los conflictos, que en su mayoría seguían siendo motivados por la posición inicial de ambas partes frente al Concordato de 1851. En este momento lo único que cambia es el enfoque, en consecuencia, mientras que para el nuevo Estado todo lo que no había sido modificado, continuaba vigente; para la Santa Sede lo único con fuerza de obligar era el nuevo Acuerdo firmado.

Pero, si el modo de ejercicio del privilegio de presentación fue el asunto que dió origen a las negociaciones, el Acuerdo fué más allá, introduciendo otros puntos que lo hicieron sumamente importante para la regulación de las relaciones Iglesia-Estado durante casi doce años. Ya que aunque en el artículo 6 se establecio: "El Gobierno español, por su parte, se compromete formalmente a concluir cuanto antes con la Santa Sede un nuevo Concordato inspirado en su deseo de restaurar el sentido católico de la gloriosa tradición nacional. El presente convenio estará en vigor hasta que se incorporen sus normas al nuevo Concordato"10; como conocemos, el nuevo Concordato no se firmaría hasta el año 53.

Merecen destacarse especialmente los artículos 9 y 10. Así, en el artículo nueve se establecía que: "Entretanto se llega a la conclusión de un nuevo Concordato, el Gobierno español se compromete a observar las disposiciones contenidas en los cuatro primeros artículos del Concordato de 1851"

De ellos, el $1^{\circ}$ es quizá el más básico: "La Religión Católica, Apostólica, Romana, que con exclusión de cualquier otro culto continúa siendo la única de la

\footnotetext{
${ }^{8}$ Vid. A. BERNARDEZ CANTON, Legislación eclesiástica del Estado (1938-1964), Tecnos, Madrid, 1965, pp. 266-268.

${ }^{9}$ Cfr. A. MARQUINA, op. cit., pp. 291-292.

${ }^{10}$ Vid. A. BERNARDEZ CANTON, op. cit., p. 267.
} 
Nación española, se conservará siempre en los dominios de S. M. Católica, con todos los derechos y prerrogativas de que debe gozar según la Ley de Dios y lo dispuesto por los sagrados cánones"; pero, comprometerse con el $2^{\circ}$ tampoco estuvo exento de importancia: "En su consecuencia, la instrucción en las Universidades, colegios, seminarios y escuelas públicas o privadas será en todo conforme a la doctrina de la misma Religión Católica; y a este fin no se pondrá impedimento alguno a los obispos y demás prelados diocesanos, encargados por su ministerio de velar sobre la pureza de la doctrina de la fe y de las costumbres, y sobre la educación religiosa de la juventud, en el ejercicio de este cargo, aún en las escuelas públicas".

Se declara y se acepta el compromiso, con los cuatro artículos cuya vigencia se rescata, de que la religión católica es la única de la nación española; se reconoce a la religión católica los derechos y las prerrogativas que le corresponden tanto según la Ley de Dios como según los sagrados cánones; se establece el compromiso por parte del Estado de que se guarde a los prelados y ministros sagrados el respeto y consideración que se les debe según los sagrados preceptos; igualmente con respecto a los obispos y clero, en cuanto pertenece al derecho y ejercicio de la autoridad eclesiástica y al ministerio de las órdenes sagradas, la libertad que establecen los sagrados cánones; y el control de la enseñanza y cultura para su inspiración en la doctrina de la religión católica ${ }^{11}$.

También y hasta que se llegue a la conclusión del nuevo Concordato, el Gobierno se compromete a no legislar sobre materias mixtas o sobre aquéllas que pudieran interesar de algún modo a la Iglesia, sin previo acuerdo con la Santa Sede ${ }^{12}$.

De los datos y pronunciamientos expuestos no resulta difícil deducir que a partir de la firma del Acuerdo del 41, las relaciones entre la Iglesia y el régimen franquista cambian, cuando menos sustancialmente ${ }^{13}$. El régimen seguía manteniendo viva la necesidad de un nuevo Concordato, pero para la Iglesia la situación no era tan apremiante puesto que los temas más urgentes ya habían quedado convenidos, a saber, el procedimiento para el nombramiento de obispos, la confesionalidad del Estado, la enseñanza conforme a la doctrina de la religión católica, la vigilancia de los prelados sobre la pureza de la doctrina de la fe, costumbres y educación religiosa de la juventud, la libre jurisdicción de los obispos y el apoyo del Gobierno en el caso de que se intentase pervertir los ánimos de los fieles y corromper sus costumbres o se hubiera de impedir la publicación, introducción o circulación de libros malos y

${ }^{11}$ Cfr. A. DE LA HERA, "La actitud del Franquismo ante la Iglesia". Iglesia católica y regímenes autoritarios y democráticos (experiencia española e italiana), Madrid, Edit. Revista de Derecho Privado, 1987.

${ }^{12}$ Art. 10 Acuerdo de 1941. Vid. A. BERNARDEZ CANTON, op. cit., p. 268.

${ }^{13}$ Según A. MARQUINA, "estos dos artículos (el 9 y el 10 anteriomente citados) tendrían una importancia decisiva. La Santa Sede, teniendo en sus manos un mini-concordato firmado, como hacen a este convenio estos dos artículos, ya no tendría ninguna prisa por la firma de un Concordato que les podría comprometer política e intemacionalmente con un régimen que, por mucho que se diga, nunca tuvo buena acogida en el Vaticano. El embajador Ruiz Gimenez se daría cuenta de inmediato del porqué de la minuciosidad vaticana y su sustituto Castiella lo primero que conseguiría sería la eliminación del artículo 10 de este Convenio. Así se pudo abrir paso a la negociación del Concordato". Op. cit., p. 291. 
nocivos, y además la imposibilidad de legislación unilateral del Gobierno sobre materias mixtas o sobre aquéllas que pudieran interesarle. La Iglesia se convertía así, o continuaba siendo, en garante de la 'moralidad pública' y además se conseguía por medio del procedimiento convenido sobre el modo de ejercicio del privilegio de presentación que gran parte de la jerarquía eclesiástica fuera 'adicta al régimen', con lo cual éste obtenía un control difícil de haber logrado únicamente con su propio y escaso aparato ideológico.

III- De todos los aspectos enunciados, hay uno sobre el que quisiéramos llamar especialmente la atención: la declaración de confesionalidad ${ }^{14}$.

Estamos en presencia de la primera declaración expresa de confesionalidad que asume el nuevo régimen, y además se plasma en un texto concordado. Si importante es la fórmula utilizada ${ }^{15}$, lo es tanto o más el iter legislativo y de intenciones seguido hasta llegar a la misma. Veámoslo.

Ya antes de finalizada la guerra, incluso en los primeros instantes del alzamiento, y antes también de que viera la luz la primera de las Leyes Fundamentales, el Fuero del Trabajo, en la zona nacional empiezan a dictarse disposiciones de muy diversa naturaleza ${ }^{16}$ cuya finalidad no es otra que la de dejar sin efecto algunas de las más significativas normas jurídicas producidas por la II República sobre el factor religioso y en consecuencia 'devolver' a la vida española la inspiración cristiana que se había tratado de suprimir.

Entre las primeras podemos citar la Orden de 4 de septiembre en virtud de la cual se dipuso que en las escuelas no pudiesen emplearse libros contrarios a los principios del dogma y de la moral cristianas; la del 21, también de septiembre , por la que se restablecía el estudio de la Religión y de la Historia Sagrada en las escuelas nacionales de enseñanza primaria. De términos y contenido similar son las Ordenes de 22 de septiembre y de 10 de noviembre para los Institutos de Enseñanza Media

\footnotetext{
${ }^{14}$ Los anteriores textos constitucionales desde la Constitución de Cádiz de 1812, recogen expresamente la confesionalidad del Estado, con excepción de las dos constituciones republicanas. N. MONTESINOS, La Confesionalidad pieza clave en la historia constitucional española y el régimen franquista, tesis doctoral leída en la Facultad de Derecho de la Universidad de Alicante en octubre de 1991.

${ }^{15}$ En el art. I del Concordato del 53 quedaría explicitada del siguiente tenor: "La Religión Católica, Apostólica, Romana sigue siendo la única de la nación española y gozará de los derechos y prerrogativas que le corresponden en conformidad con la ley divina y el derecho canónico". REGATILLO entendió que al afimar que la religión católica sigue "siendo la única de la nación española" se afirmaba un hecho histórico: "hasta ahora ha sido"; un hecho presente: "es hoy en dia"; un principio de derecho: "seguirá siendo, deberá ser en lo sucesivo". Op. cit., p. 133.

${ }^{16}$ Conviene recordar los siguiente datos:

- La Junta de Defensa Nacional (creada por Decreto de 24 de julio de 1936) designa sus poderes en don Francisco Franco, nuevo jefe del Gobiemo del Estado español, quien asumirá todos los poderes del nuevo Estado, y al que se nombra Generalísimo de los Ejércitos, el 29 de septiembre del 36.

- La Junta Técnica del Estado, con funciones gubemamentales, se crea el 1 de octubre de 1936.

- Las leyes de prerrogativa, en virtud de las cuales el General Franco gozaba de la suprema potestad de dictar normas jurídicas de carácter general, datan del 30 de enero de 1938 y del 8 de agosto de 1939.
} 
y las Escuelas Normales de Magisterio. Y, en este marco educativo, por Decreto de 23 de diciembre se prohibía la publicación y comercio de libros pornográficos ${ }^{17}$.

También se organizó, por Orden de 6 de diciembre de 1936, la asistencia religiosa a las fuerzas combatientes en las filas nacionales. Como delegado pontificio para estas atenciones espirituales actuó el Cardenal Arzobispo de Toledo, y fueron desempeñadas por los miembros de los Cuerpos de Capellanes Castrenses y de la Armada, cuya extinción había decretado la República, por los sacerdotes procedentes de remplazos llamados a filas y por los sacerdotes seculares o religiosos que se ofrecieron voluntariamente ${ }^{18}$.

E incluso muy tempranamente, en 1937, algunas conmemoraciones y fiestas religiosas se declararon fiestas nacionales, con lo que igualmente la situación volvía a la anterior a la República. Algunas de las fiestas que se recuperaron fueron: el Jueves y el Viernes Santo, el Corpus, o la Purísima Concepción. Un Decreto de 21 de julio reconocía al Apóstol Santiago como Patrón de España, y consecuentemente el 25 de julio era declarado dia de fiesta nacional.

Ahora bien, sin despreciar la importancia, significación y trascendencia 'social' de estas primeras disposiciones, hubo algunas que tuvieron una mayor repercusión, puesto que también contaron en su momento con una más amplia contestación social por parte de determinados sectores. Merecen ser citados a este respecto la Ley de 12 de marzo de 1938 por la que se derogaba la de matrimonio civil de 1932; el Decreto de 3 de mayo de 1938 por el que se restablecía la Compañía de Jesús, que había sido disuelta y cuyos bienes habían sido incautados por Decreto de 23 de enero de 1932, en virtud del polémico artículo 26 de la constitución republicana ${ }^{19}$; la Ley de 10 de Diciembre de 1938, derogatoria de la de secularización de cementerios de 30 de enero de 1932; la Ley de 2 de febrero de 1939 por la que se deroga la de Confesiones y Congregaciones Religiosas de 2 de julio de 1933 y el Decreto de 20 de agosto de 1931 relativo a la venta de bienes eclesiásticos, con lo que las Ordenes y Congregaciones Religiosas recobran la situación jurídica que tenían en España con anterioridad a la Constitución de $1932^{20}$.

\footnotetext{
${ }^{17}$ J. PEREZ GOMIS, Nueva Legislación de Educación Nacional, ALDUS, Santander, 1938. Contiene toda la legislación publicada desde julio de 1936 hasta junio de 1938, de interés para los Centros profesionales de la enseñanza y otras disposiciones de carácter general. Fue autorizada la publicación por la Comisión de Cultura y Enseñanza de la Junta Técnica del Estado.

${ }^{18} \mathrm{Cfr}$. I. MARTIN MARTINEZ, "El desarrollo de la Iglesia Española y sus relaciones con el Estado", op. cit., p. 24.

${ }^{19} \mathrm{El}$ artículo 26 establecía: "Todas las confesiones religiosas serán consideradas como asociaciones sometidas a una ley especial. El Estado, las regiones, las provincias y los municipios, no mantendrán, favorecerán ni auxiliarán económicamente a las iglesias, asociaciones e instituciones religiosas.

Una ley especial regulará la total extinción en un plazo máximo de dos años del presupuesto del clero.

Quedan disueltas aquellas órdenes religiosas que estatutariamente impongan además de los tres votos canónicos, otro especial de obediencia a autoridad distinta de la legítima del Estado. Sus bienes serán nacionalizados y afectados a fines benéficos y docentes.

Las demás órdenes religiosas se someterán a una ley especial votada por estas Cortes Constituyentes y ajustada a las siguientes bases: ...".

${ }^{20}$ Vid. A. BERNARDEZ CANTON, op. cit., pp. 3-6.
} 
Aún hubo otras disposiciones antes de finalizar la guerra con la misma finalidad restauracionista en el ámbito religioso, y que denotaban una intención de claro trato de favor a la Iglesia (nacional) y a su jerarquía. Basten como ejemplo el Decreto de 2 de marzo de 1939 sobre exención de contribución territorial a la Iglesia, completado por la Orden de 11 de marzo. Del mismo día en que finaliza la guerra, es la Orden sobre la franquicia postal en favor de Arzobispos, Obispos y Vicarios particulares; en ella expresamente se afirmaba que 'siempre' la habían disfrutado, si bien había sido suprimida por 'el espíritu sectario imperante desde la implantación de la República', y se justificaba su restablecimiento incluso a 'título de debida reparación, ${ }^{21}$.

Y como consecuencia del fin de la guerra, por ley de 8 de mayo de 1939, se anulan las resoluciones pronunciadas en zona roja. En su artículo $1^{\mathrm{o}}$ se decía: "Se priva a todas las resoluciones de cualquier clase que sean, en los órdenes civil, contencioso administrativo y penal dictadas por funcionarios extraños al Movimiento Nacional, y a partir del 18 de julio de 1936, del carácter de firmes y, en su consecuencia, no producirán los efectos de la cosa juzgada ni la excepción que la protege".

IV-Consideramos relevante traer aquí a colación el hecho de que sobre las más significativas disposiciones de carácter religioso que hasta este momento fueron dictadas por el Gobierno Nacional se pronunciaron en su dia los Obispos en documentos dirigidos en su mayoría a los fieles ${ }^{22}$.

Así, en 1931, el 9 de mayo, hablan a los fieles sobre el acatamiento del Régimen constituido y los temores de la Iglesia en el siguiente tono: "Particularmente todos y cada uno de los prelados españoles han recordado ya a los fieles los deberes que les ligan con las autoridades constituidas de cooperar al bien común y al mantenimiento del orden social (...). Los prelados españoles en su deseo sincero de no crear dificultades al Gobierno provisional, han callado hasta el presente con la esperanza de que serían por él íntegramente respetados los derechos de que por tantos títulos venía gozando la Iglesia en España. Mas su silencio pudiera ya ser interpretado fácilmente como aquiescencia a medidas del poder público y a hechos gravísimos que han producido penosísima impresión a los católicos por lesionar derechos suyos preciadísimos, por los que los prelados tienen el deber de velar, ya que pertenecen al patrimonio de la fe y de las costumbres cristianas del pueblo español..." ${ }^{23}$.

Poco después, y tal como se había anunciado en el documento anterior, el Cardenal Segura, en nombre de los metropolitanos, se dirige al presidente de la

\footnotetext{
${ }^{21}$ Ibidem, p. 11.

${ }^{22}$ Los documentos pueden consultarse en, Documentos Colectivos del Episcopado Español, B.A.C., Madrid, 1974. En 1923 se constituye la Junta de Reverendísimos Metropolitanos, pero, estrictamente hablando, la Conferencia de Metropolitanos no se constituye hasta 1946, y sus estatutos reciben la aprobación de la Santa Sede en junio de 1947.
}

${ }^{23}$ Vid. Documentos Colectivos... op. cit., pp. 130-133. 
República haciendo una exposición de los agravios que consideran han sido hechos a la religión católica y a la Iglesia ${ }^{24}$.

De nuevo el Cardenal Segura arrogándose la confianza y la representación de los Obispos $^{25}$, expone en un texto del "Episcopado a los fieles" las ideas y temores sobre el proyecto de Constitución y los deberes de los católicos ${ }^{26}$. En él se hacía la siguiente afirmación: "Porque, para decirlo desde el principio el proyecto de constitución tiene tan serios inconvenientes que, si prevaleciera tal como ha sido presentado, crearía a la Iglesia en España una situación gravísima, que a todo trance es necesario precaver si queremos evitar penosísimos males, principalmente en el orden religioso y moral aunque también trascendería al orden social y aún al mismo orden material" ${ }^{27}$.

La supresión del presupuesto del culto y clero dió lugar a que los metropolitanos se dirigieran a los fieles el 21 de noviembre de 1931. Las difíciles circunstancias por las que atravesaba la Iglesia, que en este momento inciden en el aspecto económico, dieron lugar al establecimiento de una colecta mensual para el sostenimiento de culto y clero $^{28}$.

A finales de año ${ }^{29}$ el Episcopado expone a los fieles la postura de los obispos ante la nueva Constitución: "Promulgada la Constitución española y constituidos jurídicamente todos los poderes del Estado, éntrase en una nueva etapa de la República, y ha llegado el momento de que el Episcopado dé forma solemne a su actitud ante los hechos y aleccione a los fieles para señalarles su conducta futura (...).

\footnotetext{
${ }^{24}$ El sumario del texto era el siguiente: "1 - Fue acuerdo colectivo dirigirse al presidente del Gobiemo provisional. 2- El Episcopado ha recordado a los católicos españoles el deber de obedecer a las autoridades constituidas cooperando con ellas al bien común: se esperaba, en cambio, respeto a los derechos de la Iglesia. 3- Pero los metropolitanos se ven obligados a exponer su pena ante disposiciones gubernativas incalificables, de las que dan algunas muestras. 4- Sigue la lista de trece atentados a la religión católica y a la Iglesia. 5- Con todos los buenos españoles el Episcopado protesta de los incendios de Iglesias y conventos, por lo que tienen de daño material y de sacrilegio. 6- Esperan la intervención del Presidente del gobiemo". Vid. Documentos Colectivos... op. cit., p. 133.

${ }^{25}$ E1 Cardenal Segura se encontraba en Belloc (Francia). E1 15 de junio el Ministro de la Gobemación, Miguel Maura, ordenó detenerlo y conducirlo a la frontera francesa. Ante la imposibilidad de que fuera examinado por los Obispos pidió un voto de confianza e interpretó los silencios como aprobaciones. Hubo malestar, opiniones encontradas e incluso en la prensa aparecieron dos documentos diferentes. La Santa Sede ordenó al Cardenal Segura que dejara de actuar y de publicar documentos, dada su condición de refugiado en Francia. El último documento firmado en esta época por el Cardenal data del 25 de agosto.

${ }^{26}$ De nuevo, reproducimos el sumario: "1- Se ha presentado a discusión de las Cortes el proyecto de Constitución: si se aprobara crearía a la Iglesia una situación gravísima. 2- Se implanta sin atenuaciones el laicismo del Estado. 3- En el artículo primero se da por supuesto que el poder no dimana de Dios, sino únicamente del pueblo. 4- En el artículo 8 se suprime la religión del Estado, sustituido por el ateismo del Estado. 5- Se separan Estado e Iglesia. 6- En su virtud en los artículos 8, 12, 21 y 31 se subordina la Iglesia al Estado. 7-Se establecen en los artículos 12,18, y 31 la libertad de cultos, de pensamiento, de cátedra y de conciencia. 8- Se recuerdan a los católicos y especialmente a los periodistas católicos sus deberes en circunstancias tan difíciles". Vid. Documentos Colectivos... op. cit., pp. 135-136.

${ }^{27}$ Ibidem.

${ }^{28}$ Ibididem, pp. 155-159.

${ }^{29}$ Es de diciembre de 1931, pero no va fechada.
} 
Los principios y preceptos constitucionales en materia religiosa no sólo no responden al mínimum de respeto a la libertad religiosa y de reconocimiento de los derechos esenciales de la Iglesia que hacían esperar el propio interés y dignidad del Estado, sino que inspirados por un criterio sectario, representan una verdadera oposición agresiva aun a aquellas exigencias mínimas...Más radicalmente todavía se ha cometido el grande y funesto error de excluir a la Iglesia de la vida pública y activa de la nación, de las leyes, de la educación de la juventud, de la misma sociedad doméstica, con grave menosprecio de sus derechos sagrados y de la conciencia cristiana del país, así como en daño manifiesto de la elevación espiritual de las costumbres y de las instituciones públicas. De semejante separación violenta e injusta, de tan absoluto laicismo del Estado, la Iglesia no puede dejar de lamentarse y protestar, convencida como está de que las sociedades humanas no pueden conducirse, sin lesión de deberes fundamentales, como si Dios no existiera, o rehuir el atender a la Religión como si ésta fuera un cuerpo extraño a ellas o cosa inútil y nociva". La situación era de impotencia, lo cual no impidió que se recordara expresamente que: "La Iglesia vence el mal con el bien, que responde a la iniquidad con la justicia, al ultraje con la mansedumbre, a los malos tratos con beneficios, y que en definitiva también la ciencia cristiana del sufrir es un poder de victoria: Somos maldecidos, y bendecimos; sufrimos persecución, y la soportamos; somos calumniados, y oramos ${ }^{\prime \prime 30}$, palabras con las que concluye tan significativo documento.

También respondieron los obispos a dos leyes que dan muestra de lo que ellos mismos denominan 'laicismo agresivo'. Los documentos son el de 25 de julio de 1932, sobre el matrimonio civil ${ }^{31}$ y el de 25 de mayo de 1933, último de la época republicana, antes del estallido de la guerra civil, con motivo de la Ley de confesiones y congregaciones religiosas ${ }^{32}$. Dicen los obispos que "Por graves y reveladores que fuesen los precedentes constitucionales y los actos de gobierno que han conducido a la elaboración de esta ley, no debía esperar la Iglesia el porvenir que se le depara. Si el espíritu de la Ley fundamental de la república ha sido justamente calificado de laicismo agresivo, este pretendido estatuto legal de la Iglesia ha de ser considerado como abiertamente persecutorio, pues, inspirado más bien en el viejo cesarismo, todavía agravado, que no en el criterio de libertad y justicia que informa el derecho común, tal como de la Constitución se deriva, llega a constituir una verdadera ley de excepción -ya sólo por ello recusable- opresora, ofensiva e injusta".

A partir de este momento, el episcopado callará. El próximo pronunciamiento conjunto tendrá lugar en 1937, en plena guerra, y será la ya conocida 'Pastoral colectiva del Episcopado español a los obispos del mundo sobre la guerra de España'. Y volverá de nuevo a callar durante algunos años, terminada la guerra civil y los primeros años del régimen franquista, hasta entrado el año 1948.

\footnotetext{
${ }^{30}$ Vid. Documentos Colectivos... op. cit., pp. 160-181.

${ }^{31}$ Ibidem, pp. 181-185.

${ }^{32}$ Ibidem, pp. 189-219.
} 
Por contra, la jerarquía eclesiástica española no calló y si bien no participó directamente en el alzamiento nacional ${ }^{33}$, sí que lo considera inmediatamente como un movimiento libertador de la opresión a la que había estado sometida durante la República; en consecuencia sus documentos representan una clara apología del régimen $^{34}$ la cual se fundamenta básicamente, no en unas claras convicciones políticas, sino en la lucha contra un enemigo común (la república, el comunismo), y de manera muy especial en el carácter religioso que se le otorga a la guerra por la jerarquía española de forma unilateral. Este carácter religioso resulta evidente, ya el 6 de agosto de 1936 se da la llamada pastoral conjunta de los obispos vascos; Monseñor Olaechea de Pamplona declaraba el dia 19 de ese mes que "se ventilan los sagrados intereses de la religión y de la patria", y el 23 que "no es una guerra la que se está librando, es una Cruzada". "La más santa que han visto los siglos", diría posteriormente. El arzobispo de Valladolid añadiría el 28 del mismo mes a los soldados el título de "cruzados de Cristo y de España", y el 1 de octubre el arzobispo de Granada comentaba: "nos encontramos de nuevo en Lepanto". El 15 de noviembre el arzobispo de Valladolid diría: "España está dividida en dos: de un lado los estigmatizados por el sello de la Bestia, lanzando blasfemias y sacrilegios; del otro, aquellos cuya frente y cuyo corazón están marcados por el signo salvador, el signo de Dios...Y como cristiano y español, nadie puede permanecer neutral ni espectador en esta lucha". El 30 de diciembre el de Córdoba escribiría que nos las habemos con "la Cruzada más heróica que registra la historia"35.

Otros dos documentos importantes por su especial repercusión fueron la Pastoral de Monseñor Pla y Deniel, obispo de Salamanca y la del Cardenal Gomá. Monseñor Pla y Deniel, en su Pastoral "Las dos ciudades", diría que no se puede criticar a la Iglesia "porque se haya abierta y oficialmente pronunciado a favor del orden contra la anarquía, a favor de la implantación de un gobierno jerárquico contra el disolvente comunismo, a favor de la defensa de la civilización cristiana y sus fundamentos, religión, patria y familia, contra los sin Dios y con Dios, sin patria y hospicianos del mundo, en frase feliz de un poeta cristiano"36. Por su parte, el Cardenal Gomá, que apoyó decididamente el alzamiento desde el primer dia, en su Pastoral "El caso de España", vendría a afirmar: "Esta cruelísima guerra es en el fondo una guerra de principios, de doctrinas, de un concepto de la vida y del hecho social contra otro, de

\footnotetext{
${ }^{33}$ GUY HERMET en su obra Los católicos en la España franquista. II Crónica de una dictadura, Madrid, 1986, p. 30, establece que también participaron en la sublevación de forma directa cierto número de sacerdotes y religiosos. Y con respecto al Cardenal Gomá afirma que 'parece' que había sido avisado de la fecha de la sublevación, gracias a lo cual el 18 de julio se encontraba oportunamente fuera de Toledo, habiéndose trasladado a Pamplona.

${ }^{34}$ P. 'LOMBARDIA, "La actitud de la Iglesia ante el franquismo", Iglesia Católica y regímenes autoritarios y democráticos (Experiencia española e italiana), Madrid, 1987, p. 85.

${ }^{35}$ CHAO REGO, La Iglesia en el Franquismo, Madrid, 1976, pp. 26-27.

${ }^{36}$ La Pastoral de Monseñor Pla y Deniel se publicó en el Boletín oficial de la diócesis de Salamanca. El texto es reproducido en A. MONTERO MORENO, Historia de la persecución religiosa en España, Madrid, 1961, pp. 688-708. G. SANCHEZ RECIO, De las dos ciudades a la resurrección de España. Magisterio pastoral y pensamiento político de E. Pla y Deniel (en prensa).
} 
una civilización contra otra. Es la guerra que sostiene el espíritu cristiano y español contra ese otro espíritu ${ }^{37}$. La jerarquía eclesiástica española apoya, pues, decididamente el alzamiento, rechaza la República y el comunismo ${ }^{38}$, y le atribuye a la guerra un contenido esencialmente religioso por encima del social o político, con lo que su apoyo al nuevo régimen resulta en principio sobradamente justificado.

Por contra, la importancia del tema o factor religioso no fue tomada en consideración originariamente por los alzados; ni los jefes insurrectos ni Franco ${ }^{39}$ se consideran en principio como cruzados, sino más bien como 'defensores del orden republicano ${ }^{40}$. Siendo ésta la situación, era lógico que en las primeras declaraciones públicas no se hiciera referencia alguna al factor religioso. Así, cuando el General Franco lanza el primer manifiesto de la sublevación militar, el tema religioso no aparecerá ni explícita ni implícitamente tratado, "En estos momentos es España entera la que se levanta pidiendo paz, fraternidad y justicia; en todas las regiones el ejército, la marina y fuerzas del orden público se lanzan a defender la Patria" y concluiría "haciendo reales en nuestra Patria, por primera vez y en este orden, la trilogía, fraternidad, libertad e igualdad"41. Y el 29 de julio afirmaría: "este movimiento es un movimiento nacional, español, republicano".

Además en la composición de la Junta de Defensa Nacional, creada el 23 de julio, podemos observar que su presidente, don Miguel Cabanellas era sobradamente conocido como liberal, moderado y masón, y que entre sus miembros, sólo algunos que constituían un grupo minoritario, habían participado activamente en el catolicismo. Tampoco en el programa de dicha Junta se encuentra ninguna alusión al tema o problemática religiosa ${ }^{42}$. Y, es más, el general Franco en el discurso que pronuncia con ocasión de su elevación a la jefatura del Estado, el 1 de octubre, se referiría a la problemática religiosa en términos como estos: "El Estado, sin ser confesional, concordará con la Iglesia Católica, respetando la tradición nacional y el sentimiento religioso de la inmensa mayoría de los españoles, sin que ello signifique

\footnotetext{
${ }^{37}$ Vid. J. GOMA Y TOMAS, Pastorales de la guerra de España, Madrid, 1955.

${ }^{38}$ Lo cual no supone una innovación que pueda serle atribuida a la jerarquía eclesiástica española, ni tan siquiera se hace tomando como fundamento exclusivo la experiencia vivida por la Iglesia en España, sino que se desarrolla y aplica la doctrina pontificia que desde Gregorio XVI efectúa una crítica del liberalismo, del Estado liberal y del materialismo ateo.

${ }^{39}$ En lo concemiente a la trayectoria religiosa y católica de Franco pueden verse: J. P. FUSI, Franco. El País-Aguilar, Madrid, 1985. J. TUSELL, Franco en la guerra civil. Una biografía política, Tusquets, Barcelona, 1992. S.G. PAYNE, Franco. El perfil de la historia, Espasa Calpe, Madrid, 1992.

${ }^{40} \mathrm{Cfr}$. GUY HERMET.....PAYNE afirma que "se proponían instaurar un régimen más autoritario y conservador, dominado por los militares. La religión no tenía ningún papel oficial en esa empresa. Algunos de los activistas militares no sentían ningún interés por la defensa del catolicismo, mientras que otros se mostraban renuentes a complicar aún más la situación dando a su movimiento un tono religioso. Los rebeldes esperaban un apoyo extenso de las clases medias y no deseaban provocar el antagonismo de los anticlericales moderados. Por eso, sus primeras declaraciones, en los comienzos del conflicto, no hicieron ninguna referencia a la cuestión religiosa".

${ }^{41}$ Vid. F. DIAZ-PLAJA, La guerra de España en sus documentos, Madrid, 1986, p. 24.

42 Ibidem., pp. 24-26 para la creación y programa de la Junta de Defensa Nacional.
} 
intromisión ni reste libertad para la dirección de las funciones específicas del Estado"43.

De todas formas sí pueden encontrarse algunas referencias al tema religioso, quizá porque el léxico y tonos utilizados eran propios de la estructura y tradición castrense, quizá porque la dirección militar decidiera aprovechar el apoyo que se le brindaba. Por ejemplo, el general Mola, a finales de julio, empleó la frase "la verdadera España católica" $^{\text {"44 }}$. Y en el mes de agosto, cuando el mismo general Mola pronuncia un discurso por radio contestando a las palabras del señor Martínez Barrio, diría: "Se nos pregunta de otro lado a dónde vamos. Es fácil y ya lo hemos repetido muchas veces. A imponer el orden, a dar pan y trabajo a todos los españoles y a hacer justicia por igual. Y luego, sobre las ruinas que el frente popular deja -sangre, fango y lágrimas-, edificar un Estado grande, fuerte, y poderoso, que ha de tener por galardón y remate allá en la altura una cruz de ámplios brazos, señal de protección a todos. Cruz sacada de los escombros de la España que fue, pues es la cruz que es símbolo de nuestra religión y de nuestra fe, lo único que ha quedado a salvo entre tanta barbarie que intentaba teñir para siempre las aguas de nuestros ríos con el carmín glorioso y valiente de la sangre española"45. Pero aunque el tema religioso aquí sí aparezca expresamente mencionado, ello no significa que sea, ni que se convierta, en el motivo fundamental de la guerra, que como hemos visto era la argumentación que utilizaba de forma reiterada el episcopado en sus primeros pronunciamientos.

V- Resulta cuando menos llamativo, tal como antes advertía, el hecho de que con posterioridad el episcopado en su conjunto guarde un mutismo tan significativo, el cual sólo va a romper en 1937 con la conocida Pastoral Colectiva y en 1948 con la Instrucción sobre la Propaganda protestante en España ${ }^{46}$. Silencio que podría tener muy diferentes interpretaciones y que incluso como ellos mismos dijeron en mayo de 1931, podría entenderse como "aquiescencia" con las medidas tomadas por el Nuevo Régimen.

De no ser esa la interpretación, cómo se entiende que la Iglesia calle ante las atrocidades cometidas en la guerra, ante las matanzas indiscriminadas.

Tampoco se oye su voz de manera clara al finalizar la contienda ${ }^{47}$. Ahora bien, la victoria franquista colocará a la Iglesia en una nueva situación que la hará buscar

\footnotetext{
${ }^{43}$ El texto entrecomillado guarda grandes analogías con el punto 25 de la Falange. Pudo ser realizado por Martinez Fuset según establece E. VEGAS LATAPIE, Los caminos del desengaño. Memorias políticas (II) 1936-1938, Tebas, Madrid, 1988.

44 Vid. M. TUÑON DE LARA, El hecho religioso en España, París, 1968, p. 134.

${ }^{45}$ Vid. F. DIAZ PLAZA, op. cit., pp. 57-59.

${ }^{46}$ Textos íntegros en Documentos Colectivos...op. cit., pp. 219-242 y 242-249 respectivamente.

${ }^{47}$ N. MONTESINOS SANCHEZ, "Notas sobre las relaciones entre la Iglesia y el gobiemo del general Franco durante la guerra çivil", Anales de la Universidad de Alicante. Facultad de Derecho, $\mathrm{n}^{\circledR} 4,1989$, pp. 155-174.
} 
metas más ambiciosas en sus demandas al Estado y en su posición en el marco nacional; intentará reconquistar el espacio perdido, reconfesionalizar al Estado y recristianizar al pueblo. Pero aún así callará.

Por su parte, el nuevo Estado en su proceso de estructuración y definición continuará su andadura legal sin dejar de hacer mención de la Iglesia, la Religión Católica, o incluso la Ley de Dios en sus diferentes disposiciones. Y ello desde los primeros momentos, $y$ en leyes de muy distinto rango normativo.

Ya a partir del Fuero del Trabajo y en las siete Leyes Fundamentales ${ }^{48}$ que configuran el máximo techo legal de esta época, la actitud originariamente manifestada por el Jefe del Estado en orden al marco en el que debían desarrollarse las relaciones Iglesia-Estado, se modificaría sustancialmente. La renovación de la tradición española que constituye el glorioso pasado, pasa necesariamente (así se entiende), por la renovación de la tradición católica. Unidad nacional y unidad espiritual se presentan como un binomio inseparable.

Antes del Acuerdo sobre el modo de ejercicio del Privilegio de Presentación, al que me he referido, y antes del fin de la guerra, por ley de 9 de marzo de 1938 se dicta el Fuero del Trabajo ${ }^{49}$ en un momento no especialmente distendido en las relaciones entre la Iglesia y el nuevo régimen en gestación y en el que las posturas que se adopten influirán decisivamente en la configuración posterior de las relaciones entre ambos poderes. Mientras que por un lado el General Franco necesitaba el apoyo y el reconocimiento de la Iglesia en su conjunto, de la Iglesia a nivel internacional; ya que pese a sentirse satisfecho con los apoyos y ayudas expresos y manifiestos que se le brindaban por la Iglesia a nivel nacional, éstos no eran suficientes por sí solos para el logro de sus objetivos, los cuales trascendían las fronteras nacionales. La Iglesia a nivel internacional, por su parte, no estaba dispuesta a acceder a priori a tales pretensiones sin obtener nada a cambio, y con el más que probable deterioro que para su imagen internacional podía acarrearle tal toma de posición.

Quizá será por todo ello, y porque, aunque los proyectos y aspiraciones son firmes en este terreno, todavía no se puede asegurar cuál será el desenlace de la guerra, por lo que en el Fuero del Trabajo se establecen tan sólo tímidas manifestaciones y declaraciones de principios en favor de la Iglesia y de la religión católica, pero sin que ni una ni otra aparezcan mencionadas. Especialmente expresiva resulta la Exposición de Motivos, la cual puede ponerse en relación con el principio XV. La importancia de estos textos es quizá mayor por lo que pueden encerrar y por lo que de ellos puede derivarse que por lo que literalmente establecen. Se dice en la Exposición de Motivos: "Renovando la tradición católica de justicia social y alto sentido humano que informó la legislación de nuestro glorioso pasado, (...), subordinando la economía a la dignidad de la persona humana, teniendo en cuenta sus necesidades materiales y las exigencias de su vida intelectual, moral, espiritual y religiosa, (...). El Estado español formula estas declaraciones, que inspirarán su

\footnotetext{
48 Vid. Leyes Fundamentales del Reino, Biblioteca Oficial Legislativa (B.O.L.), Madrìd, 1975.

${ }^{49}$ El Fuero del Trabajo fue modificado por la Ley Orgánica del Estado de 10 de enero de 1967. Vid. Leyes Fundamentales..., op. cit., pp. 29-55.
} 
política social y económica"50. Y en el principio XV: "En la fecha en que esta Carta se promulga, España está empeñada en una heroica tarea militar, en la que salva los valores del espíritu y la cultura del mundo a costa de perder buena parte de sus riquezas materiales"51. Existen además algunos otros pronunciamientos que merecen ser destacados como por ejemplo la alusión a Dios como fuente de la que emana el deber al trabajo, y en la que encuentra apoyo el correlativo derecho, establecidos ambos para el cumplimiento de los fines individuales y la prosperidad y grandeza de la Patria ${ }^{52}$. En el principio segundo se contiene otra declaración interesante: "El Estado mantendrá el descanso dominical como condición sagrada en la prestación del trabajo", y a reglón seguido: "sin pérdida de la retribución y teniendo en cuenta las necesidades de las empresas, las leyes obligarán a que sean respetadas las fiestas religiosas y civiles declaradas por el Estado" ${ }^{\text {53 }}$.

Con todo, se hace de la tradición católica estandarte por el que merece la pena luchar y que sirve, pese a no haber sido tomado originariamente en consideración, para aglutinar fuerzas muy diversas que la admiten como justificación hacía el interior y como tarjeta de presentación hacia el exterior, mayormente una vez publicada la Carta Colectiva. Todas estas declaraciones serían presentadas en Roma por la Jerarquía eclesiástica española, y en especial por el Cardenal Gomá, como pruebas del buen hacer, de la buena voluntad del nuevo régimen, con lo cual, este, indirectamente iba alcanzando sus objetivos. La Iglesia en su conjunto seguía sin pronunciarse.

Las declaraciones continuaron con la segunda de las Leyes fundamentales con la que se proseguía la configuración de la estructura jurídico-constitucional. La Ley Constitutiva de las Cortes es de 17 de julio de $1942^{54}$, con ella no desaparece la suprema potestad de dictar normas jurídicas de carácter general que al Jefe del Estado atribuían las leyes de treinta de enero de 1938 y de ocho de agosto de $1939^{55}$, sino que sencillamente el órgano que con dicha ley se crea "significará, a la vez que eficaz instrumento de colaboración en aquella función, principio de autolimitación para una institución más sistemática del poder".

Si tenemos presente que las Cortes son el órgano superior de participación del pueblo español en las tareas del Estado, y que es misión principal de las mismas la elaboración y aprobación de las leyes, sin perjuicio de la sanción que corresponde

\footnotetext{
${ }^{50}$ Fuero del Trabajo, Leyes Fundamentales..., op. cit., p. 18.

${ }^{51}$ Ibidem, p. 29.

${ }^{52}$ Fuero del Trabajo, principio I,3. Leyes Fundamentales..., op. cit., p. 19.

${ }^{53}$ Fuero del Trabajo, principio II. Leyes Fundamentales..., op. cit., pp. 20-21. La Ley de Descanso Dominical es de 13 de julio de 1940 (BOE de 18 de julio) y su reglamento fue aprobado por Decreto de 25 de enero de 1941 (BOE del 5 de marzo). El calendario oficial de fiestas fue aprobado por Decreto de 23 de Diciembre de 1957 (BOE de 1 de enero de 1958). Además, el 12 de octubre era considerado como fiesta nacional, y el primero del mismo mes, como fiesta oficial a todos los efectos, excepto los laborales. El día primero de mayo era inhábil a todos los efectos.
}

${ }^{54}$ Ley Constitutiva de las Cortes. Leyes Fundamentales..., op. cit., pp. 55-64.

${ }^{55}$ Las ya conocidas leyes de prerrogativas. 
al jefe del Estado; es de destacar que cuando en el artículo segundo se regula su composición, en el apartado d) se dice que entre sus Procuradores estarán "aquellas personas que por su jerarquía eclesiástica, (...), designe el Jefe del Estado, oído el Consejo del Reino, hasta un número no superior a veinticinco" ${ }^{156}$. Además hay que tener presente que las modificaciones que introduce en esta Ley la Ley Orgánica del Estado años después, serán para dar entrada a un nuevo grupo de Procuradores representantes de la familia, pero los Procuradores de la jerarquía eclesiástica designados por el Jefe del Estado, continuarán existiendo ${ }^{57}$. El Estado pues, se mantiene en la línea de no efectuar un reconocimiento formal de la Iglesia o de la religión católica, pero amplía progresivamente sus lazos de unión con ellas al reconocer a la jerarquía eclesiástica (de la Iglesia católica nacional aunque no aparezca citada en el texto), y en especial a las personas que de entre ellas designe el Jefe del Estado, por el procedimiento un año antes acordado, no sólo como componentes de las Cortes, sino como representantes del pueblo español, a tenor de lo establecido en el artículo segundo, $\mathrm{II}^{58}$. Los Procuradores en Cortes acreditarán ante el Presidente de las mismas la elección, designación o cargo que les de derecho a tal investidura. El Presidente de las Cortes les tomará juramento, dará posesión y expedirá los títulos correspondientes. Este juramento se hará ante Dios, con lo que se recoge la fómula utilizada en los textos confesionales mayoritarios en la historia constitucional española, fórmula que aparecerá posteriormente también en otras leyes $^{59}$.

Y será finalmente en el Fuero de los Españoles de 17 de julio de $1945^{60}$, texto definidor de los derechos y deberes de los mismos y amparador de sus garantías, tal como se establece en su Exposición de Motivos y aunque en ocasiones estos derechos se convirtieran en letra muerta al no ser exigible su aplicación y cumplimiento ante ningún tribunal ${ }^{61}$; donde se consagre por vez primera en un texto no concordado la confesionalidad ${ }^{62}$. En efecto, el artículo $6^{\circ}$, en su redacción originaria

${ }^{56}$ Ibidem, p. 59.

${ }^{57}$ Exposición de Motivos de la Ley Constitutiva de las Cortes, Ibidem, p. 56.

58 Artículo en el que se establecía: "Todos los Procuradores en Cortes representan al pueblo español, deben servir a la nación y al bien común y no están ligados por mandato imperativo alguno".

${ }^{59}$ El juramento ya quedó establecido en la Constitución de Cadiz de 1812.

${ }^{60}$ Fuero de los Españoles, Leyes Fundamentales..., op. cit., pp. 9-18. N. MONTESINOS SANCHEZ, "La confesionalidad del régimen franquista a través del Fuero de los Españoles y de la Ley de Principios del Movimiento Nacional", Iglesia, Sociedad y Estado en España, Francia e Italia (ss. XVIII al XX), Instituto de Cultura "Juan Gil-Albert", Alicante, 1991, pp. 451-462. A. SANCHEZ DE LA TORRE, Comentario al Fuero de los Españoles, I.E.P., Madrid, 1987. J. XIFRA HERAS, Fuero de los Españoles, Enciclopedia jurídica Seix.

${ }^{61} \mathrm{~J}$. SOLE TURA, Introdución al régimen político español, Ariel, Barcelona, 1971.

${ }^{62}$ En el punto 25 de la Falange, no modificado trás la unificación, se establecía: "Nuestro movimiento incorpora el sentido católico -de gloriosa tradición en España- a la reconstrucción nacional. La Iglesia y el Estado concordarán sus facultades respectivas, sin que se admita intromisión o actividad alguna que menoscabe la dignidad del Estado o la integridad nacional". Vid. F. DIAZ-PLAJA, La España Franquista en sus documentos, 1976, p. 168. 
establecía: "La profesión y práctica de la Religión Católica que es la del Estado español, gozará de la protección oficial. Nadie será molestado por sus creencias religiosas ni el ejercicio privado de su culto. No se permitirán otras ceremonias ni manifestaciones externas que las de la religión católica"63.

Los primeros compromisos formales que en materia eclesiástica y al más alto nivel que adopta el nuevo Estado se refieren a la religión católica, a sus ministros y a las leyes divina y canónica; y de manera especial se compromete con la religión católica, a la que por ser la religión del Estado español protegerá. La opción por la que el Estado se decanta es la de adherirse a una religión, la iglesia tendrá cabida porque es la conjunción del grupo de creyentes en tal fe y la encargada de dirigirlos. El Estado le atribuye a la Iglesia un papel capital, en cuanto que ni conoce la doctrina a la que se adhiere si no se la propone la Iglesia, ni las leyes divina y canónica sino en cuanto las formula la Iglesia, ni determina por sí mismo a qué jerarquía y ministros ha de aceptar y proteger, ni qué acción van a ejercitar libremente en el seno de la sociedad española puesto que también la Iglesia determina ambos datos. El Estado acepta la existencia de una jerarquía de la Iglesia cuyas facultades de acción reconoce y, reconocidas permite que actuen de facto con eficacia jurídica en el ámbito de la soberanía estatal. Y dado que todo esto se opera mediante la decisión del Estado de no ejercer su soberanía en el terreno eclesiástico, el propio Estado cede o reconoce a la Iglesia esa soberanía que él no va a ejercitar ${ }^{64}$.

Y aún así, y pese al reconocimiento formal y expreso de la religión católica, la Iglesia nacional callará.

VI- La Iglesia consigue parte de sus objetivos, reconfesionaliza al Estado, a la sociedad $^{65}$, sus ministros gozan de gran autoridad, controla la formación de la juventud, etc. Pero ¿paga con su silencio o queda encorsetada, encerrada en la letra de tantas y tantas disposiciones que le son a priori favorables? ¿Es capaz de valorar la significación de su silencio, de su aquiescencia y de su colaboración en la formación del consenso que apoyaría el desarrollo del régimen? ${ }^{66}$. Muchas cuestiones están ya dilucidadas, en otras sería necesario incidir ya que son muchos los interrogantes que continuan abiertos.

El Régimen definido por el propio Franco en uno de sus famosos discursos en términos suficientemente expresivos "No somos un paréntesis ni una dictadura entre dos tiempos como nuestros adversarios pretenden. Construimos una verdadera

\footnotetext{
${ }^{63}$ El Fuero y el artículo $6^{\circ}$ fueron aprobados por aclamación en medio de gritos entusiásticos al jefe del Estado. Un buen número de las enmiendas que se presentaron al mismo pueden encontrarse en, D. BASTERRA, El derecho a la libertad religiosa y su tutela jurídica, Civitas, Madrid, 1989.

${ }^{64}$ A. DE LA HERA, op. cit., pp. 49-51.

${ }^{65}$ Aunque sea en ocasiones de manera forzada y gracias a la protección oficial que el Estado otorga a la religión católica, lo que imposibilita la práctica libre de otros cultos.

${ }^{66}$ A. BOTTI, Cielo y dinero. El Nacionalcatolicismo en España (1881-1975), Alianza, Madrid, 1992.
} 
rectificación histórica, un orden nuevo fruto del genio español, creado por nuestro movimiento en 1936 en una hora de fracaso rotundo de los viejos sistemas"67, conseguirá sin ser, mientras no se demuestre lo contrario su propósito inicial, un estado confesional. Pero no un Estado confesional de corte idéntico a la confesionalidad española del XIX, sino probablemente un estado confesional moderno gracias al cual, y en virtud del cual garantizar su continuidad en el tiempo.

Quizá la confesionalidad sea ya tema manido por ampliamente debatido, pero tal vez sea todavía clave interpretativa suficiente para coordinar diferentes y nuevos enfoques desde los que entender el porqué de una época y sus consecuencias.

\footnotetext{
${ }^{67}$ Discurso pronunciado por el Jefe del Estado ante las Cortes españolas el 18 de mayo de 1958.
} 